\title{
Extinction following separate-phase acquisition: Effects of shifts in reinforcement percentage and N-length
}

\author{
DENNIS G. DYCK, K. MICHAEL DRESEL, ROBERT B. THIESSEN \\ and VINCENT Di LOLLO \\ University of Manitoba, Winnipeg, Manitoba, Canada R3T 2N2
}

\begin{abstract}
Fox (1972) found that separate-phase shifts in N-length produced changes in postshift performance similar to contrast effects. The study, however, confounded shifts in N-length and in reward percentage. In the present study $\mathrm{N}$-length shifts produced changes in postshift performance only when attended by reward percentage shifts but not in isolation. Extinction was not influenced by $\mathrm{N}$-length shift either in isolation or in combination with reward percentage shift. However, training with constant $\mathrm{N}$-lengths of three produced more resistance to extinction than constant training with $\mathrm{N}$-lengths of one. The results were viewed to be at variance with a reward-level/sequential model (Capaldi, Note 1), but consonant with an emphasis on the role of frustrative stimulus control.
\end{abstract}

Reinforcement parameters such as magnitude and percentage exert quite different influences on extinction performance when presented in isolation (Hulse, 1958; Wagner, 1961) than when combined across separate phases of acquisition (Capaldi, 1974, Note 1; Hulse, 1973). These results, which point to an interaction between reward magnitude, percentage, and order, raise the question of whether other parameters of reinforcement schedule interact in 'a similar manner. One such parameter shown to exert a powerful influence on the course of extinction following a single phase of extended acquisition is $\mathrm{N}$-length, the number of successive nonrewarded trials preceding reward (cf. Capaldi, 1967).

Preliminary evidence (Fox, 1972) suggests that bidirectional shifts between N-lengths of three and one influence early postshift performance in much the same manner as shifts in reward magnitude. However, since $\mathrm{N}$-length and reward percentage were confounded in Fox's (1972) study, the contrast-like effects cannot be unambiguously ascribed to shifts in $\mathrm{N}$-length alone.

The present experiment examined the effect of $\mathrm{N}$-length shifts in isolation by holding reward percentage constant. Furthermore, we sought to determine the degree to which early postshift performance could predict extinction performance. The latter issue is of considerable relevance to recent accounts of instrumental learning which posit similar mechanisms to account for contrast effects (particularly negative contrast) and extinction performance (cf. Capaldi, 1974, Note 1; McHose \& Moore, 1976).

This research was supported by National Research Council of Canada Grant A9941 to the first author. Requests for reprints should be sent to Dennis G. Dyck, Department of Psychology, University of Manitoba, Winnipeg, Manitoba, Canada R3T 2N2.

\section{METHOD}

\section{Subjects}

The subjects were 48 90-day-old male albino Sprague-Dawley rats from the Holtzman Company. The subjects were randomly assigned to one of six groups ( $n=8$ per group), but one subject from two of the conditions died, leaving those two groups with seven subjects.

\section{Apparatus}

A single runway, $158.8 \mathrm{~cm}$ long, made by Hunter was used for the experiment. The runway was constructed with Plexiglas walls $(12.7 \mathrm{~cm}$ high) and ceiling $(9.2 \mathrm{~cm}$ wide). The floor was made with aluminum bars (centers $1.3 \mathrm{~cm}$ apart). Two electronically operated black guillotine doors separated runway into startbox (31.9 cm long), run section ( $94.0 \mathrm{~cm}$ long), and goalbox ( $31.8 \mathrm{~cm}$ long). An opaque glass food cup was at the distal end of the goalbox.

The subject's progress was monitored by two Standard timers, accurate to $.01 \mathrm{sec}$. The first timer started when the startbox door was opened and stopped when the beam to a photocell, $79.4 \mathrm{~cm}$ fro:n the startbox door, was broken. The second timer started when the first timer stopped and was in turn stopped by a second photocell, $33.0 \mathrm{~cm}$ from the first (18.4 cm inside the goalbox).

Run and goal speeds were obtained by reciprocating first and second timer readings, and total speed was obtained by summing the two times and then taking the reciprocal.

\section{Procedure.}

Water was freely available throughout the experiment. For the first 7 days after arrival at the laboratory, the subjects also received ad-lib food. After the 7-day acclimatization period, the subjects were all placed on a 12-g/day food deprivation schedule, which was then maintained for the duration of the experiment.

After 10 days of deprivation, the experiment started. On reinforced trials $(R)$ subjects received eight $.045 \mathrm{~g}$ Noyes pellets, and on nonreinforced trials $(\mathrm{N})$ subjects were confined in the unbaited goalbox for $20 \mathrm{sec}$. Table 1 contains a listing of the groups with their schedules of reward and the number of subjects per group. Phases 1 and 2 lasted 12 days each and extinction lasted 10 days. 
Table 1

Reward Schedules

\begin{tabular}{llll}
\hline Group & \multicolumn{1}{c}{ Phase 1 } & \multicolumn{1}{c}{ Phase 2 } & Extinction \\
\hline Fox 13 & NRNR & NNNRNNNR & NNNNNNN \\
Fox 31 & NNNRNNNR & NRNR & NNNNNNN \\
& RNRNRNR & RRNNNRR & \\
N 13 & NRNRNRN & RNNNRRR & NNNNNNN \\
& RNRNRNR & NNNRRRR & \\
& RRNNNRR & RNRNRNR & \\
N 31 & RNNNRRR & NRNRNRN & NNNNNNN \\
& NNNRRRR & RNRNRNR & \\
& RNRNRNR & RNRNRNR & \\
N 1 & NRNRNRN & NRNRNRN & NNNNNNN \\
& RNRNRNR & RNRNRNR & \\
& RRNNNRR & RRNNNRR & \\
N 3 & RNNNRRR & RNNNRRR & NNNNNNN \\
& NNNRRRR & NNNRRRR & \\
& & & \\
\hline
\end{tabular}

Note-For Groups Fox 13 and Fox 31, $n=7$; for all other groups, $n=8$.
As can be seen from Table 1, all groups received seven trials per day during extinction. Group Fox 13 received four trials per day in Phase 1 and eight trials per day in Phase 2. Group Fox 31 was the reverse condition, eight trials per day in Phase 1 and four trials per day in Phase 2. All other groups received seven trials per day, with the first schedule listed being given on Day 1, the second on Day 2, and the third on Day 3. This cycle was then repeated until the end of the phase, so that subjects experienced each schedule four times per phase. Subjects were run in squads of three, with one rat receiving all trials for that day before the next rat received any trials (ITI $=1 \mathrm{~min})$.

\section{RESULTS}

Figure 1 shows the performance of each of the groups in the goal measure of the runway. Since performance was similar in each of the runway measures, only the results of the goal measures are reported.

The analyses on Phase 1 acquisition training yielded a significant main effect for groups $[\mathrm{F}(3,42)=4.94$,

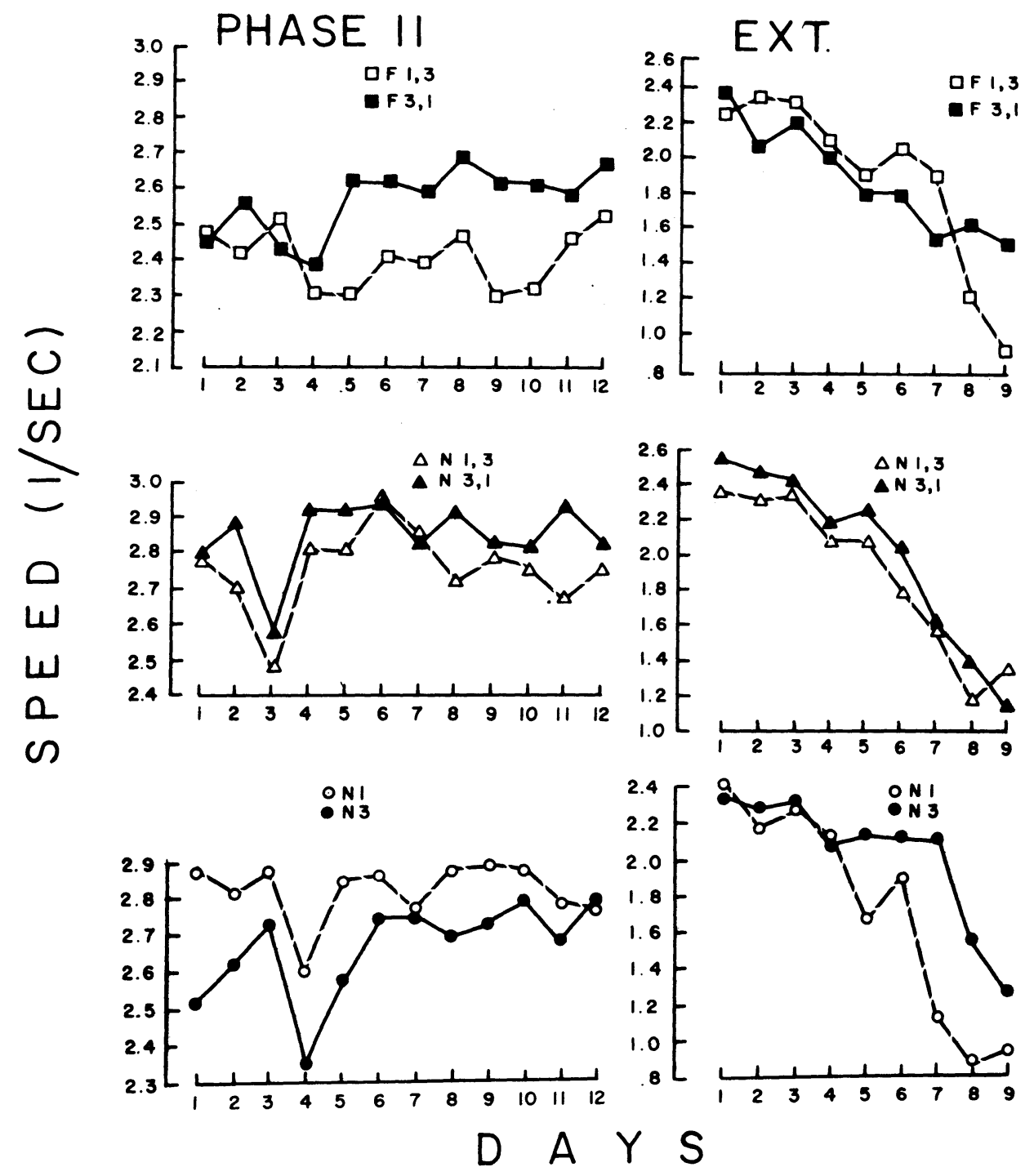

Figure 1. Mean daily speed in the goal section during Phase 2 and extinction as a function of training treatment. 
$p<.011$. It should be noted that the Fox conditions received nonreward on the first trial of each day. Consequently, the inferior performance of the Fox conditions is in large part attributable to slow speeds on the first trial of the day, which was reflected by the significant Group by Day interaction $[F(33,462)=10.93, p<.01]$. The interaction indicates that the difference between the Fox conditions and the remaining groups increased over days; as would be expected on the basis of patterned running in the former groups. Of course, days was highly significant as a source of variance in both runway measures.

The analyses of Phase 2 (postshift) once again indicated a significant main effect of groups $[F(5,40)=2.53, p<.05]$. In addition, the Group by Day interaction was significant $[F(55,440)=2.47$, $p<.01]$. A breakdown of this interaction revealed two statistically significant comparisons. First, the comparison of F13 vs. F31 was significant on Days 5-10 (ps <.05). As Figure 1 shows, Group F31 was superior to Group F13, thereby confirming the major finding of Fox (1972). Second, as in Phase 1, the two Fox conditions ran more slowly than the remaining four conditions $(p<.05)$. It is noteworthy that the comparison involving shifts in $\mathrm{N}$-length with reward percentage held constant (e.g., N13 vs. N31) was not significant on any day.

The analysis on extinction did not reveal a significant main effect for groups $[F(5,40)=.79, p<.05]$. However, the interaction was significant $[\mathrm{F}(40,320)=1.74$, $p<.01]$. Post hoc comparisons on the interaction yielded one significant effect; namely, the conventional N-length comparison involving Groups $\mathrm{N} 1$ and N3. The comparison between these groups was significant on Days 7,8 , and 9 (ps $>.01)$.

\section{DISCUSSION}

Significant changes in postshift performance were found with concomitant shifts in $\mathrm{N}$-length and reward percentage. On the other hand, when reward percentage was held constant, no change in postshift performance was found as a function of $\mathrm{N}$-length shift. Since we did not include a condition where percentage was varied and $\mathrm{N}$-length was held constant, it can only be concluded that N-length shifts in isolation do not affect postshift performance.

This finding is inconsistent with Capaldi's recent integration of the reward level concept with sequential variables (cf. Capaldi, Note 1). Reward level theory assumes that instrumental conditioning occurs when obtained reward exceeds expected reward. Conversely, unconditioning (or inhibition) is assumed to accrue whenever expected reward exceeds obtained reward. In an earlier version (Capaldi, 1974), expected reward level was assumed to vary as a function of molar reward parameters, such as percentage and magnitude. More recently, Capaldi (Note 1) has suggested that subjects may generate expectancies at a more molecular level (i.e., subjects may store and retrieve expected reward levels which correspond to parameters of reward associated with internal nonreward-reward stimuli). On this view, subjects exposed to a $50 \%$ schedule of reinforcement develop expected reward levels unique to the schedule- generated cues (SR1, SR2, SN1, SN2, etc.). Thus, for example, subjects exposed to a schedule containing only $\mathrm{N}$-lengths of one are assumed to develop, in addition to a molar expected reward level, an expectancy unique to the memory stimulus occasioned by one nonreward trial (SN1). Since the percentage of reinforcement is $100 \%$ with respect to $\mathrm{SN} 1$, a high expected reward level would develop with respect to that stimulus. This would not be the case, however, for a subject trained on a schedule containing only $\mathrm{N}$-lengths of three, since the percentage of reinforcement associated with $\mathrm{SN} 1$ as well as SN2 would be zero. Viewed within this framework, shifts in N-length amount to shifts in reward percentage. We found this line of theorizing both intriguing and plausible. Indeed, together with the Fox (1972) report, it served to stimulate the present study. Unfortunately, the postshift data reported here do not support this approach.

The reward-level/sequential view (Capaldi, Note 1) also failed to gain support from the present extinction data. Based on our understanding of this view, we predicted that a shift from longer to shorter N-lengths would be associated with greater resistance to extinction relative to a shift in the opposite direction. Clearly, this prediction was not supported, even when density was confounded with $\mathrm{N}$-length. It should be noted that Groups F13 and F31 differed in postshift but not in extinction. This finding is inconsistent with the emphasis of recent theories (Capaldi, 1974; McHose \& Moore, 1974) that changes in early postshift behavior (i.e., contrast effects) involve processes similar to those involved in extinction following separate-phase acquisition.

In our view there may be merit in distinguishing between factors that affect the respective appearance and dissipation of contrast effects; notably, negative contrast. It may well be that negative contrast dissipates because frustrative stimuli acquire control over behavior. Further, it is likely that frustrative stimuli will regulate extinction performance following the downshift. In any event, the relationship between postshift performance and extinction is not straightforward and is likely dependent on factors such as the duration of the preceding downshift phase, the magnitude of the downshift, and similar factors.

The present discussion has focused on effects which did not conform to theoretical expectation. Obviously, the processes which regulate extinction following separate-phase acquisition are somewhat more complex than those processes attending simple one-phase acquisition-extinction designs, and are as yet not adequately identified by theory. In our view the conventional $\mathrm{N}$-length extinction effects observed in the present study merit little discussion since those effects are reasonably well accounted for by sequential theory (Capaldi, 1967).

\section{REFERENCE NOTE}

1. Capaldi. E. J. Reinforcement level: An expectancy-associative approach to relative reinforcement and nonreinforcement effects. In the Arlington symposium on learning. Symposium presented at the University of Texas at Arlington, February 1975.

\section{REFERENCES}

Capaldi, E. J. A sequential hypothesis of instrument learning. In K. W. Spence \& J. T. Spence (Eds.). The psychology of learning and motivation (Vol. 1). New York: Academic Press. 1967. Pp. 67-156.

CAPAldi, E. J. Partial reward either following or preceding consistent reward: A case of reinforcement level. Journal of Experimental Psychology, 1974, 102. 954-962.

Fox, P. A. Reward- and nonreward-produced stimuli and performance to patterned reinforcement. Journal of Comparative and Physiological Psychology. 1972. 80. 342-348. 
Hulse, S. H., JR. Amount and percentage of reinforcement and duration of goal confinement in conditioning and extinction. Journal of Experimental Psychology, 1958, 56, 48-57.

Hulse, S. H. Patterned reinforcement. In G. H. Bower (Ed.), The psychology and learning and motivation (Vol. 7). New York: Academic Press, 1973. Pp. 313-362.

MCHose. J. H.. \& Moore, J. N. Expectancy, salience and habit: A noncontextual interpretation of the effects of changes in the conditions of reinforcement on simple instrumental responses Psychological Review. 1976, 83. 292-307.

WAGNER. A. R. Effects of amount of percentage of reinforcement and number of acquisition trials on conditioning and extinction. Journal of Experimental Psychologv, 1961, 63, 234-342.

(Received for publication August 1, 1977.) 